\title{
Pelatihan pembuatan Herbarium untuk menunjang pembuatan museum Kebun Raya Liwa dan pemberdayaan teknisi di UPTD Kebun Raya Liwa (KRL) Kabupaten Lampung Barat
}

Yulianty*, Rochmah Agustrina, Eti Ernawiati, Lili Chrisnawati, Ayu Meilani, Firly Arliandi, \& Hambali

Program Studi Biologi Jurusan Biologi FMIPA, Universitas Lampung

* yoelisoeradji@yahoo.co.id

Abstrak. Indonesia merupakan negara dengan keanekaragaman tumbuhan yang tinggi. Salah satu cara untuk mengenal tumbuhan yang ada adalah kebun Raya. Potensi kebun raya ini belum maksimal digunakan sebagai tempat untuk mengenalkan tumbuhan baik untuk pelajar maupun masyarakat umum. Keterlibatan staf yang ada di UPTD Kebun Raya Liwa sangat diperlukan untuk mengoleksi langsung tumbuhan yang diamati dan membuat herbarium untuk memudahkan pengenalan tumbuhan yang ada di KR. Pelatihan pembuatan herbarium ini diawali dengan pre-test untuk mengetahui kemampuan dari staff KRL dalam mengoleksi tumbuhan yang akan dibuat herbarium, dilanjutkan dengan pemberian materi teknik pembuatan herbarium tumbuhan serta praktik lapangan. Akhir pelatihan, staf KRL diberi posttest untuk mengetahui peningkatan pengetahuan dalam mengoleksi tumbuhan. Hasil pelatihan ini terjadi peningkatan nilai sebesar 31,54 dan persentase peningkatan pengetahuan adalah sebesar 56,94\%. Dengan terjadinya peningkatan pengetahuan dan keterampilan tersebut. Peserta pelatihan dapat membuat herbarium untuk tumbuhan yang ada di Kebun Kebun Raya Liwa dan untuk jangka panjang herbarium yang telah dibuat dapat diletakkan di Museum KRL.

Kata Kunci: herbarium, kebun raya liwa, lampung barat

\begin{abstract}
Indonesia is a country with high plant diversity. One way to get to know the plants is the Botanical Garden. The potential of this botanical garden has not been maximally used as a place to introduce plants for both students and the general public. The involvement of staff at UPTD Kebun Raya Liwa is necessary to collect the observed plants directly and make herbarium to facilitate the introduction of plants in KRL. This herbarium manufacturing training begins with a pre-test to know the ability of krl staff in collecting plants to be made herbarium, followed by the provision of plant herbarium making techniques and field practices. At the end of the training, KRL staff were given a post-test to find out the increased knowledge in making herbarium. The result of this training was an increase in value by 31.54 and the percentage increase in knowledge was $56.94 \%$. The improvement of knowledge and skills for making herbariums in the long term, herbarium can be placed in the KRL Museum.
\end{abstract}

Keywords: herbarium, liwa botanical garden, west lampung

To cite this article: Yulianty., R. Agustrina., E. Ernawiati., L. Chrisnawati., A. Meilani., F. Arliandi., \& Hambali. 2020. Pelatihan pembuatan Herbarium untuk menunjang pembuatan museum Kebun Raya Liwa dan pemberdayaan teknisi di UPTD Kebun Raya Liwa (KRL) Kabupaten Lampung Barat. Unri Conference Series: Community Engagement 2: 459-463. https://doi.org/10.31258/unricsce.2.459-463

(C) 2020 Authors

Peer-review under responsibility of the organizing committee of Seminar Nasional Pemberdayaan Masyarakat 2020 


\section{PENDAHULUAN}

Indonesia merupakan negara dengan keanekaragaman hayati yang besar, contohnya keanekaragaman tumbuhan. Sebagai salah satu bagian dari pelajaran IPA, keanekaragaman tumbuhan diperkenalkan kepada siswa pada semua jenjang pendidikan (SD, SMP dan SMA). Menurut Suyatna (2017), Ilmu pengetahuan alam (IPA) merupakan pengetahuan yang dapat diperoleh dengan pengumpulan data dari eksperimen, pengamatan, dan deduksi untuk menghasilkan suatu penjelasan tentang sebuah gejala yang dapat dipercaya. Salah satu cara untuk mengungkap keanekaragaman tumbuhan yang ada dapat diperoleh melalui Kebun Raya.

Kebun Raya Indonesia (KRI) memiliki tanggung jawab untuk melaksanakan upaya konservasi tumbuhan dan penelitian di Indonesia. Pada kenyataannya, empat kebun raya yang dikelola oleh LIPI baru mampu mengkonservasi sekitar 21,5\% dari seluruh tumbuhan terancam kepunahan Indonesia. Oleh karena itu, diperlukan pengembangan Kebun Raya Daerah (KRD) untuk mengkonservasi tumbuhan pada tiap daerah di Indonesia. (Purnomo, et al. (2015).

Kebun Raya yang berada di Lampung adalah Kebun Raya Liwa. Menurut Lalika et al. (2020), Kebun Raya Liwa memiliki potensi untuk dikembangkan pengelolaannya mulai dari segi keindahan alamnya, pendidikannya, serta pemanfaatannya. Persepsi pengunjung menunjukkan bahwa secara umum objek daya tarik, infrastruktur, fasilitas dan prasarana tergolong cukup,

Berdasarkan pengamatan dan kunjungan ke Kebun Raya Liwa, koleksi tumbuhan yang ada terutama yang spesifik di Kebun Raya Liwa belum semuanya dibuat herbarium. Adapun tujuan pembuatan herbarium itu untuk mempelajari lebih lanjut tanaman tersebut sehingga ada data yang valid tentang tanaman itu yang dikhawatirkan akan terancam punah. Pengamatan selanjutnya adalah herbarium yang ada belum banyak jumlahnya dan belum dibuat sesuai dengan standar seperti yang ada di Herbarium Bogoriense.

Terbatasnya sumber daya manusia (staf) yang ada menyebabkan pengetahuan dan teknik pembuatan herbarium tidak dibuat sesuai standar yang telah ditentukan. Hal ini tentu saja akan menghambat proses pembuatan museum yang salah satunya adalah berisi koleksi herbarium tanaman spesifik yang ada di Lampung Barat. Sehingga perlu dilakukan pelatihan dalam pembuatan herbarium bagi Staf UPTD KRL.

Adapun tujuan dari kegiatan ini bertujuan untuk memberikan pengetahuan dan keterampilan dalam membuat Herbarium untuk dijadikan herbarium yang standar dan tumbuhan spesifik yang ada di Lampung Barat.

\section{METODE PENERAPAN}

Pelaksanaan kegiatan pelatihan dilakukan secara ceramah, diskusi, dan praktik. Metoda ceramah dan diskusi digunakan untuk menyampaikan materi mengenai informasi konsep pengenalan tumbuhan dan cara pengoleksian tumbuhan yang baik dan benar. Setiap peserta mendapatkan handout untuk materi ini pada saat pendaftaran ulang, sehingga pada saat penyampaian materi berlangsung para peserta tidak perlu mencatat sehingga perhatian dapat terfokus untuk menyimak dan aktif mengikuti diskusi mengenai materi yang disampaikan. Sedangkan metode praktik dilakukan agar para staf KRL memiliki keterampilan cara mengoleksi keanekaragaman tumbuhan dalam bentuk herbarium. Sebelum dilakukan pelatihan diberikan pretest untuk mengetahui pemahaman mereka tentang herbarium.

Seluruh tahap-tahap kegiatan pengabdian dapat dilihat pada rincian sebagai berikut

a. Persiapan.

Kegiatan dalam persiapan pelaksanaan pelatihan/workshop meliputi:

1. pembuatan makalah materi pelatihan

2. Penyusunan soal pre-test/post test

b. Pembukaan Pelatihan

Kegiatan pelatihan diawali dengan pemberian pre-test kepada peserta pelatihan yang berisi tentang :

1. Jumlah peserta yang pernah membuat herbarium

2. Bagian organ tumbuhan herba yang akan dibuat herbarium

3. Ukuran sampel tumbuhan semak, perdu, atau pohon yang akan dibuat herbarium

4. Alat tulis yang digunakan dalam mencatat karakter tumbuhan

5. Bagian tumbuhan yang dikoleksi untuk herbarium

6. Sampel tumbuhan yang tinggi dapat dilakukan dengan penekukan sampel.

7. Bagian tumbuhan paku yang perlu didokumentasikan

8. Inisial kolektor yang ditulis pada etiket gantung

9. Letak penempelan etiket tempel herbarium 


\section{c. Penyampaian materi}

Pemberian materi bertujuan untuk memberikan pengetahuan tentang pengenalan dan pembuatan koleksi keanekaragaman tumbuhan yang disampaikan dengan metoda ceramah dan diskusi. Materi pelatihan meliputi informasi tentang pentingnya pengenalan suatu tumbuhan dan praktek pembuatan koleksi keanekaragaman tumbuhan dalam bentuk herbarium.

d. Pelatihan

Dalam kegiatan ini, tim menyediakan berbagai bahan tumbuhan yang mudah ditemui dan diperoleh dari lingkungan sekitarnya. Berdasarkan informasi mengenai pengenalan dan pembuatan koleksi tumbuhan yang telah disampaikan, para peserta(staf) dibimbing untuk mempraktekkan cara pembuatan koleksi tumbuhan dalam bentuk herbarium. Buku Acuan yang digunakan adalah Djarwaningsih, dkk. (2002) dan Ristoja (2015). Sedangkan untuk identifikasi Tumbuhan acuan yang digunakan adalah Cronquist (1981); Van Steenis, C.G.G.J (2008); The Angiosperm Phylogeny Group (2003); Tjitrosoepomo (1989) dan Tjitrosoepomo (1989).

e. Setelah penyampaian materi dan praktik selesai, peserta (staff) kembali diberi post-test untuk mengetahui seberapa besar materi ceramah dan pelatihan dapat dipahami peserta (staff).

\section{HASIL DAN KETERCAPAIAN SASARAN}

Evaluasi pelaksanaan pelatihan ini diberikan pada awal pelatihan, dimana peserta diberikan pretest. Jumlah peserta yang mengikuti pelatihan sebanyak 26 orang. Jumlah peserta yang sudah pernah membuat herbarium sebanyak 12 peserta $(46,15 \%)$, sedangkan 14 peserta $(53,85 \%)$ belum pernah membuat herbarium. Pengetahuan tentang bagian tumbuhan herba yang harus dibuat herbarium terdapat 20 peserta $(76,92 \%)$ dengan jawaban yang benar yaitu akar, batang, daun, dan bunga, sementara yang menjawab bagian lain sebanyak 6 peserta $(23,08)$. Pengetahuan tentang ukuran sampel herbarium yang diambil dari lapangan terdapat 18 peserta $(69,23 \%)$ yang menjawab dengan benar yaitu $30-40 \mathrm{~cm}$ dan 8 peserta menjawab dengan ukuran yang lain yaitu $10-15 \mathrm{~cm}$ dan $21-25 \mathrm{~cm}$. Semua peserta (100\%) mengetahui jenis pensil yang digunakan untuk menulis di paspor tumbuhan yaitu dengan menggunakan pensil 2B. Bagian tumbuhan yang dikoleksi untuk herbarium berupa organ vegetatif dan organ generatif, Pertanyaan ini dijawab dengan benar oleh 20 peserta (76,92\%), sementara 6 peserta $(23,08 \%)$ menjawab dengan salah. Untuk pertanyaan tumbuhan yang berhabitus tinggi dapat ditekuk atau dilipat dengan huruf $V$ terbalik, peserta yang menjawab benar ada 15 peserta $(57,69 \%)$ dan sebanyak 11 peserta $(42,31)$ menjawab dengan huruf $C$ terbalik. Untuk urutan pembuatan herbarium, hanya 3 peserta $(11,54 \%)$ yang menjawab dengan benar, sedangkan sebanyak 23 peserta yang tidak mengetahui urutan pembuatan herbarium. Pertanyaan tentang dokumentasi yang dilakukan pada tumbuhan paku adalah permukaan atas dan permukaan bawah, Hanya 8 peserta $(30,77 \%)$ yang menjawab dengan benar, sementara 18 peserta $(69,23 \%)$ menjawab dengan sorus. Jumlah peserta yang mengetahui cara penulisan inisial kolektor di etiket gantung ada 24 peserta $(92,31 \%)$ dan 2 peserta menjawab dengan salah. Pertanyaan tentang letak etiket tempel herbarium yang harus diletakkan di sebelah kiri bawah herbarium dijawab dengan benar oleh 13 peserta (50\%) dan 13 peserta (50\%) menjawab dengan salah.

Peningkatan pengetahuan dan keterampilan peserta pelatihan dalam pembuatan herbarium dapat dilihat pada Tabel 1.

Tabel 1. Penilaian Peningkatan Pengetahuan Peserta Pelatihan

\begin{tabular}{cccccc}
\hline No & Peserta & Pretest & Post Test & Peningkatan (poin) & Peningkatan (\%) \\
\hline 1 & A & 70 & 90 & 20 & 28,57 \\
2 & B & 60 & 90 & 30 & 50,00 \\
3 & C & 60 & 90 & 30 & 50,00 \\
4 & D & 60 & 90 & 30 & 50,00 \\
5 & E & 60 & 90 & 30 & 50,00 \\
6 & F & 50 & 90 & 40 & 80,00 \\
7 & G & 70 & 90 & 20 & 28,57
\end{tabular}




\begin{tabular}{|c|c|c|c|c|c|}
\hline 8 & $\mathrm{H}$ & 60 & 90 & 30 & 50,00 \\
\hline 9 & I & 50 & 90 & 40 & 80,00 \\
\hline 10 & $\mathrm{~J}$ & 50 & 90 & 40 & 80,00 \\
\hline 11 & K & 70 & 90 & 20 & 28,57 \\
\hline 12 & $\mathrm{~L}$ & 70 & 90 & 20 & 28,57 \\
\hline 13 & M & 70 & 90 & 20 & 28,57 \\
\hline 14 & $\mathrm{~N}$ & 50 & 90 & 40 & 80,00 \\
\hline 15 & $\mathrm{O}$ & 50 & 90 & 40 & 80,00 \\
\hline 16 & $\mathrm{P}$ & 70 & 90 & 20 & 28,57 \\
\hline 17 & $\mathrm{Q}$ & 50 & 90 & 40 & 80,00 \\
\hline 18 & $\mathrm{R}$ & 60 & 90 & 30 & 50,00 \\
\hline 19 & $\mathrm{~S}$ & 50 & 90 & 40 & 80,00 \\
\hline 20 & $\mathrm{~T}$ & 80 & 90 & 10 & 12,50 \\
\hline 21 & $\mathrm{U}$ & 50 & 90 & 40 & 80,00 \\
\hline 22 & $\mathrm{~V}$ & 60 & 90 & 30 & 50,00 \\
\hline 23 & $\mathrm{~W}$ & 50 & 90 & 40 & 80,00 \\
\hline 24 & $X$ & 50 & 90 & 40 & 80,00 \\
\hline 25 & $\mathrm{Y}$ & 60 & 100 & 40 & 66,67 \\
\hline 26 & $\mathrm{Z}$ & 50 & 90 & 40 & 80,00 \\
\hline Rata2 & & 58,8462 & $90,3846[\mathrm{~L} 1]$ & 31,5385 & 56,9460 \\
\hline
\end{tabular}

[L1] Penilaian terhadap kegiatan pretest maupun posttest mohon diuraikan sehingga peningkatan seperti apa yang dihasilkan dari sebelum pengabdian dan setelah pengabdian.

Tabel 1. menunjukkan adanya peningkatan pengetahuan dari peserta pelatihan ini. Hal ini dapat dilihat dari nilai rata-rata pretest adalah 58, 85. Setelah dilakukan pelatihan, terjadi peningkatan hasil post-test yaitu 90,38. Terjadi peningkatan poin sebesar 31,54 . Sedangkan persentase peningkatannya adalah sebesar 56,95\%. Adanya peningkatan tersebut, menunjukkan pemahaman peserta pelatihan meningkat setelah diberikan pelatihan. Harapan ini bertujuan agar peserta pelatihan dapat membuat herbarium sesuai standar yang telah ditentukan. Aturan-aturan dalam pembuatan herbarium dapat dipahami dengan baik dan benar. Peningkatan pemahaman peserta pelatihan yang penting dalam pelatihan ini adalah ukuran sampel tumbuhan yang digunakan untuk herbarium yaitu 30 x $40 \mathrm{~cm}$. Hal ini disebabkan karena contoh herbarium yang ada di KRL belum memenuhi standar yaitu kurang dari $30 \mathrm{~cm}$. Demikian pula untuk pembuatan herbarium berhabitus herba yang tinggi dapat ditekuk dengan membentuk huruf v terbalik. Selain itu peningkatan pemahaman terdapat pada urutan -urutan dalam pembuatan herbarium. Pemahaman istilah-istilah pengepresan, pengeringan, penempelan atau mounting jarang mereka dengar dan jarang mereka lakukan. Hal yang tak kalah penting adalah pada saat pengambilan sampel herbarium harus selalu disertai dengan etiket gantung, agar nomor koleksi, nama kolektor dan tanggal koleksi sampel herbarium terdata dengan baik. Tahap terakhir yang dipahami peserta setelah pelatihan adalah peletakan etiket tempel herbarium yang benar yaitu di sebelah kiri bawah herbarium.

Herbarium yang sudah ada di masa mendatang dapat diletakkan di Museum KRL. Selain adanya herbarium tersebut, perlu dikembangkan pembuatan Herbarium Book sebagai media pembelajaran. Menurut Dzikrullah 
et al. (2017), Herbarium Book ini merupakan kumpulan herbarium kering yang disatukan hingga membentuk sebuah buku, media ini disusun menggunakan kertas karton dengan ukuran A3. Jangka panjang selanjutnya adalah perlu dibuat Data Base tentang tumbuhan yang ada di KRL dengan Pembuatan Sistem Informasi Inventarisasi Tanaman Berbasis QR code untuk identifikasi tanaman yang ada di KRL.

Menurut Khaira et al. (2020), QR code sebagai penanda tanaman yang dapat dipindai menggunakan smartphone. Dengan begitu pengunjung dapat mengakses informasi detail mengenai tanaman.

\section{KESIMPULAN}

Terjadi peningkatan pengetahuan peserta pelatihan dalam membuat herbarium dan poin peningkatan nilainya sebesar 31,54 dan persentase peningkatannya sebesar 56,94.

\section{UCAPAN TERIMA KASIH}

Penulis mengucapkan terima kasih kepada DIPA BLU Universitas Tahun Anggaran 2020 yang telah membiayai kegiatan Pengabdian Kepada Masyarakat ini dengan No Kontrak 1764/UN26.21/PM/2020, Tanggal 24 Maret 2020. Penulis juga mengucapkan terima kasih kepada Balitbangda Lampung Barat dan UPTD KRL serta Staf yang telah memberikan waktu dan tempat untuk pelaksanaan kegiatan Pengabdian Kepada Masyarakat.

\section{DAFTAR PUSTAKA}

Cronquist, A. 1981. An Integrated System of Classification of Flowering Plants. New York: Columbia University Press.

Dikrullah, Muh. Rapi, and Jamilah. 2018. Pengembangan Herbarium Book Sebagai Media Pembelajaran Biologi Pada Mata Kuliah Struktur Tumbuhan Tinggi. Jurnal Biotek, 6 (1), 15-21.

Djarwaningsih, T, S. Sunarti and K. Kramadibrata. 2002. Panduan Pengolahan dan Pengelolaan Material Herbarium Serta Pengendalian Hama Terpadu di Herbarium Bogoriense. Pusat Penelitian Biologi LIPI, Bogor.

Khaira, Ulfa, Tri Suratno, Mauladi, Reni Aryani, and Edi Saputra. 2020. Pembuatan sistem informasi inventarisasi tanaman berbasis QR code untuk identifikasi tanaman Taman Hutan Kota HM Sabki Kota Jambi. Riau Journal of Empowerment, 3(2), 69-78. https://doi.org/10.31258/raje.3.2.69-78

Lalika, Haqfini Bina, Susni Herwanti, Indra Gumay Febryano,and Gunardi Djoko Winarno. 2020. Persepsi Pengunjung Terhadap Keberadaan Ekowisata Kebun Raya Liwa. Jurnal Belantara, 3(1), 25-311. https://doi.org/10.29303/jbl.v3i1.19

Purnomo, Danang Wahyu, Mahat Magandhi, and Farid Kuswantoro. 2015. Pengembangan Koleksi Tumbuhan Kebun Raya Daerah Dalam Kerangka Strategi Konservasi Tumbuhan di Indonesia. Buletin Kebun Raya, 18(2).

Riset Tumbuhan Obat dan Jamu. 2015. Eksplorasi Pengetahuan Lokal Etnomedisin dan Tumbuhan Obat di Indonesia Berbasis Komunitas. Kementerian Kesehatan Indonesia.

Suyatna, Agus. 2017. Pembelajaran Ilmu Pengetahuan Alam Wahana Untuk Menumbuhkan Kemampuan Berpikir, Bersikap, dan Bertindak Ilmiah. Prosiding Seminar Nasional: Membangun Guru Pendidikan Dasar Yang Profesional dan Berkarakter. Direktorat Pembinaan Guru Pendidikan Dasar. Direktorat Jenderal Guru dan Tenaga Kependidikan. 1-20. ISBN 978-602-61646-1-2. Jakarta.

Van Steenis, C. G. G. J. 1980. Flora Untuk Sekolah di Indonesia. Terjemahan Moeso Soerjowinoto. Jakarta: PT. Pradnya Paramita.

The Angiosperm Phylogeny Group. 2003. An Update of the Angiosperm Phylogeny Group Classification for the Orders and Families of Flowering Plants: APG III. Botanical Journal of the Linnean Society. 161, 105-121.

Tjitrosoepomo, G. 1989. Taksonomi Tumbuhan Schizophyta, Thallophyta, Bryophyta, Pteridophyta. Yogyakarta: Universitas Gadjah Mada Press

Tjitrosoepomo, G. 1989. Taksonomi Tumbuhan Tinggi. Yogyakarta. Universitas Gadjah Mada Press. 